\title{
Effects of pH, Photoperiod, and Nutrient on Germination and Growth of Calymperes erosum C. Muell. Gemmaling
}

\author{
Anthony Zinno Ogbimi, Yetunde Biodun Owoeye, \\ Victor Oluwaseyi Ibiyemi, and Akpos Valentino Bofede \\ Department of Botany, Obafemi Awolowo University, PMB 013, Ile-Ife, Nigeria \\ Correspondence should be addressed to Anthony Zinno Ogbimi; zinno2002@yahoo.com
}

Received 30 September 2014; Revised 10 December 2014; Accepted 16 December 2014; Published 31 December 2014

Academic Editor: Curtis C. Daehler

Copyright ( 2014 Anthony Zinno Ogbimi et al. This is an open access article distributed under the Creative Commons Attribution License, which permits unrestricted use, distribution, and reproduction in any medium, provided the original work is properly cited.

\begin{abstract}
Effects of $\mathrm{pH}$, photoperiod, and substrate nutrient concentration on the rate of germination of the gemmae and primary protonema growth of Calymperes erosum C. Muell. were studied. There was a statistically significant difference in germination of C. erosum gemmae and protonema growth among the different substrate $\mathrm{pH}$ levels, photoperiod treatments, and substrate nutrient conditions, respectively $(P<0.01)$. Gemmae germination and protonemal growth peaked at $\mathrm{pH} 4$ and 5 . Protonemal growth was retarded at $\mathrm{pH} 2,3,6$, and 7. No germination was observed in continuous darkness. Germination and protonema growth increased significantly $(P<0.01)$ within the first 3 and 6 hours of daylight but not again until after 9 and 12 hours of exposure, respectively. No statistical $(P>0.05)$ increase in germination and protonemal growth was observed when the nutrient concentration was increased from $25 \%$ to $200 \%$. Results indicate the moss is adapted to low nutrients and that it may germinate well at substrate $\mathrm{pH}$ as low as 2 howbeit the probability of establishment will remain limited until $\mathrm{pH}$ levels improve to 4 or 5 . Furthermore, the moss is able to achieve net photosynthetic carbon gain during morning hours. Recovery from photoinhibition is likely by evening.
\end{abstract}

\section{Introduction}

Plants being mostly immobile generally survive changes in seasons by having different life cycle stages that are adapted to different conditions. Bryophytes are able to react quickly to climatic flux due to their short life cycle and the ease with which they disperse their spores [1]. Although spores are their means of sexual reproduction, asexual propagules are now being considered to play significant role in reproduction in mosses [2-7].

Species of the Calymperaceae are widespread, occurring in the tropical and subtropical zones of the world [8]. In the humid forest of West Tropical Africa the genus Calymperes occurs mostly as epiphytes where it produces both gemmiferous and nongemmiferous leaves [9]. While gemmae are produced freely, sporophytes in this moss are reported to be rare [9]. Propagules of the moss become detached from the parent plant and are dispersed onto a spectrum of substrates and environmental conditions, where a few germinate and grow into new leafy gametophores [8].
A combination of factors control growth in plants. Abiotic factors such as $\mathrm{pH}$ level, photoperiod, and nutrient could have profound influence on the establishment of asexual propagules such as gemmae. For example, naturally occurring concentrations of humic acid reduced spore germination and retarded bud formation in Funaria hygrometrica [10] and spores of Bartramidula bartramioides germinated best in continuous light [11]. This study was undertaken to determine the effects of $\mathrm{pH}$, photoperiod, and nutrient availability on the establishment of Calymperes erosum C. Muell. gemmae.

\section{Materials and Methods}

Calymperes erosum shoots with mature gemmae were taken from their natural population on a Terminalia catappa host tree at the Obafemi Awolowo University Campus, Ile-Ife $\left(07^{\circ} 31^{\prime} 07.2^{\prime \prime} \mathrm{N}, 04^{\circ} 31^{\prime} 34.4^{\prime \prime} \mathrm{E}\right)$. The shoots were placed in a brown envelop and taken to the laboratory for further studies. 
TABLE 1: Quantity of natural light over the area, measured every three hours. SD represents standard deviation.

\begin{tabular}{lccccc}
\hline & \multicolumn{4}{c}{ Quantity of light $\left(\mu\right.$ moles $\left./ \mathrm{m}^{2} / \mathrm{s}\right) \pm$ SD } \\
6 am (0 hours) & 9 am (3 hours) & 12 noon $(6$ hours $)$ & 3 pm (9 hours) & 6 pm $(12$ hours $)$ & 9 pm \\
\hline $0.19 \pm 0.05$ & $816 \pm 32$ & $2564 \pm 104$ & $2339 \pm 96$ & $305 \pm 9$ & $0.006 \pm 0.004$ \\
\hline
\end{tabular}

2.1. $p H$ Effect. Liquid medium was prepared using normal strength Knop's solution [12]. Equal portions of the solution were added into separate conical flasks and their $\mathrm{pH}$ was adjusted to $\mathrm{pH}$ values of $2,3,4,5,6$, and 7 , respectively. The $\mathrm{pH}$ of the medium was adjusted by dropwise addition of $0.1 \mathrm{~N} \mathrm{HCl}$ or $0.1 \mathrm{~N} \mathrm{NaOH}$ and verified with a $\mathrm{pH}$ meter (Kent EIL 7055). The medium was then autoclaved at 15 psi for 15 minutes. The medium was then added into appropriately labeled Petri dishes. Gemmiferous leaves were carefully removed from their shoots and sterilized in $0.1 \%$ hypochlorite solution for one minute. The gemmae were then sown on the liquid medium in the Petri dishes. The Petri dishes were then covered and placed on the window sill of the laboratory at room temperature of $28 \pm 2^{\circ} \mathrm{C}$. The quantity of light over the area, measured at three-hour intervals, is presented in Table 1.

2.2. Photoperiod Effect. Knop's solution [12] with $\mathrm{pH}$ value of 4 , as prepared above, was used in this experiment. Some quantity of the medium was added into appropriately labeled Petri dishes. Gemmae, sterilized as above, were sown on the liquid medium in the Petri dishes. The Petri dishes were subjected to treatments of 0 hours (complete darkness throughout), 3 hours, 6 hours, 9 hours, and 12 hours of natural day light, and control, respectively, at room temperature of $28 \pm 2^{\circ} \mathrm{C}$. The control experiment was allowed natural day light, without any form of artificial exclusion or addition of light throughout the period of the experiment. The quantity of light over the area, measured at three-hour intervals, is presented in Table 1. Black, opaque polyethylene bags were used, per treatment, to exclude light from the culture as per their respective treatments. Assessment of the sown gemmae was done at the end of the experiment.

2.3. Nutrient Status Effect. Liquid medium of the following concentrations of Knop's solution was used: $0 \%, 25 \%, 50 \%$, $100 \%$, and $200 \%$. The $\mathrm{pH}$ of the medium was adjusted to 5 and then autoclaved as above. Some quantity of the medium was then added into appropriately labeled Petri dishes and gemmae, sterilized as above, were then sown on the liquid medium in the Petri dishes. The Petri dishes were then covered and placed on the window sill of the laboratory at room temperature of $28 \pm 2^{\circ} \mathrm{C}$.

Knop's solution employed was made using $250 \mathrm{mgL}^{-1}$ $\mathrm{KH}_{2} \mathrm{PO}_{4}, \quad 250 \mathrm{mgL}^{-1} \mathrm{KCl}, 250 \mathrm{mgL}^{-1} \quad \mathrm{MgSO}_{4} \cdot 7 \mathrm{H}_{2} \mathrm{O}$, $1000 \mathrm{mgL}^{-1} \mathrm{Ca}\left(\mathrm{NO}_{3}\right)_{2}$, and a trace of $\mathrm{FeCl}_{3}$. Approximately 150 gemmae were sown per Petri dish. Three replicates per treatment were used in all the experiments. Direct microscopic count was used to assess development in the gemmae. The number of nongerminated and germinated gemmae and the length of the primary protonemata in ten microscopic fields per Petri dish were recorded. An ocular

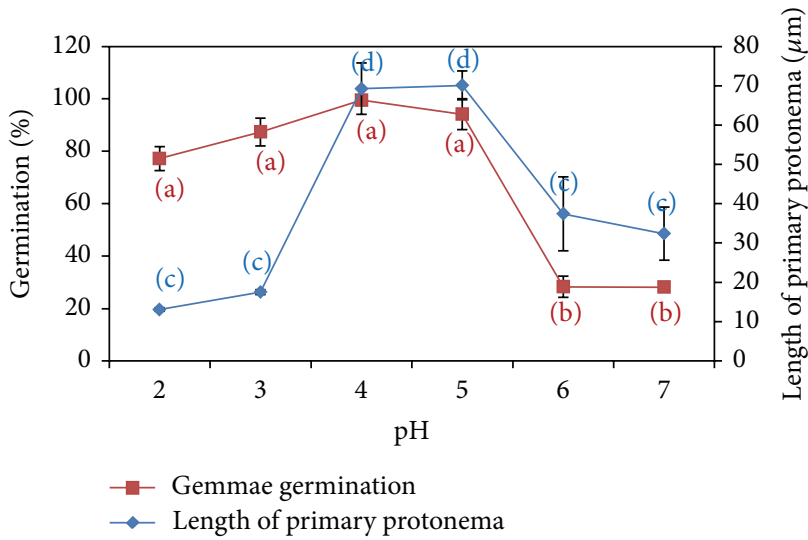

Figure 1: Effect of $\mathrm{pH}$ on gemmae germination (after 10 days) and growth of primary protonema (after 11 days) of C. erosum. Points are means of three replicates. Vertical bars represent standard error. Values with the same alphabets along the same curve are not statistically different at $1 \%$ probability.

micrometer was used to measure the length of the primary protonema. Mean and standard error values were calculated and one-way ANOVA was used to test for differences in means among treatments of $\mathrm{pH}$, photoperiod, and nutrient experiments, respectively. All observations were made using a dissecting microscope (SERIES 880, Swift Instruments International, Japan) and compound light microscope (XSZ-107BN, Olympus).

\section{Results}

There was a statistically significant difference in germination of C. erosum gemmae among the different substrate $\mathrm{pH}$ levels (Figure 1$)$ as determined by one-way $\operatorname{ANOVA}(F(5,11)=$ 57.6; $P<0.01)$. A Tukey post hoc test revealed that although rate of germination in the gemmae was not significantly different among substrates with $\mathrm{pH}$ values $2,3,4$, and 5, it was however significantly reduced in substrates with $\mathrm{pH}$ 6 and 7, respectively. There was no statistical difference in germination between substrate of $\mathrm{pH} 6$ and 7. There was a statistically significant difference in the primary protonemal growth (Figure 1) of the moss among the different substrate pH levels $(F(5,12)=19.1 ; P<0.01)$. The best growth in primary protonema occurred in medium of $\mathrm{pH} 4$ and 5 and the growth at both $\mathrm{pH}$ levels was significantly higher than that in $\mathrm{pH} 2,3,6$, and 7 , respectively. There was no statistical difference in primary protonemal growth between $\mathrm{pH}$ levels 2 and $3(P=0.992)$, 4 and $5(P=1)$, and 6 and $7(P=0.987)$.

Gemmae germination and primary protonema growth of $C$. erosum under different photoperiods are shown in 


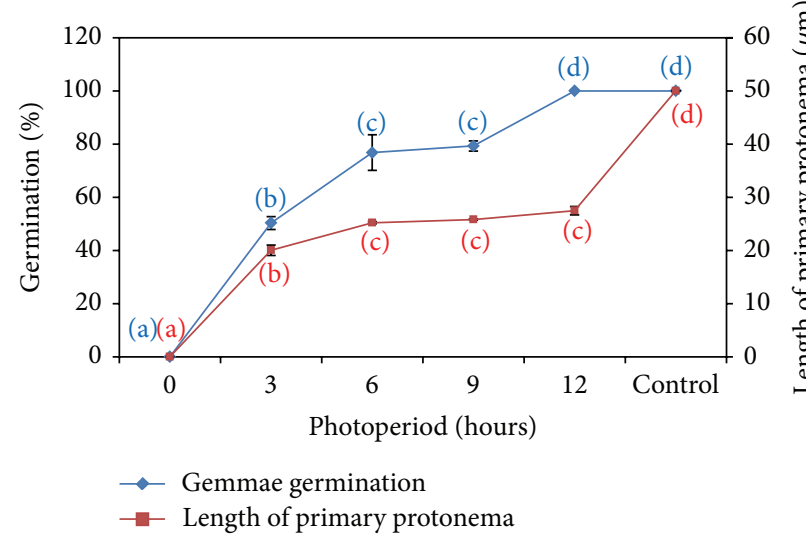

FIGURE 2: Effect of photoperiod on gemmae germination (after 8 days) and primary protonema growth (after 9 days) of C. erosum. Points are means of three replicates. Vertical bars represent standard error. Values with the same alphabets along the same curve are not statistically different at $1 \%$ probability.

Figure 2. There was a statistically significant difference in germination of C. erosum gemmae among the different exposure periods (Figure 2) as determined by one-way ANOVA $(F(5,12)=159.4 ; P<0.01)$. The post hoc test revealed that the first three hours of natural light improved, significantly, the germination percentage $(50 \pm 2.43 ; P<0.01)$ of the gemmae, which failed to germinate in continuous darkness during the period of the experiment. An additional three hours of exposure also resulted in a further significant increase in germination percentage $(76.8 \pm 6.7 ; P<0.01)$. Germination however failed to show further increase on extension of exposure to natural light up to 9 hours but improved when exposure was sustained up to 12 hours, resulting in $100 \%$ germination in the gemmae in 8 days.

Analysis of primary protonema growth under same conditions also revealed a statistically significant difference in the growth among the different exposure periods $(F(5,11)=$ 707.4; $P<0.01)$. While no primary protonema growth was observed in continuous darkness, exposure to the first 3 and 6 hours of natural daylight resulted in statistically significant growth of $20 \pm 0.98 \mu \mathrm{m}(P<0.01)$ and 25 $\pm 0.21 \mu \mathrm{m}(P<0.01)$, respectively. Growth of primary protonema remained statistically unchanged in 9 and 12 hours of exposure but improved and increased significantly when exposure was sustained beyond 12 hours, as indicated by the control experiment.

Figure 3 shows gemmae germination and primary protonemal growth of $C$. erosum in different nutrient concentrations. A one-way ANOVA $(F(4,10)=9.8 ; P<0.01)$ reveals that a statistically significant difference in germination of C. erosum gemmae exists among substrate nutrient concentrations (Figure 3) howbeit a Tukey post hoc test revealed that this difference exists only between germination in distilled water $(0 \%)$ and all the other nutrient conditions tested. While no germination was observed in distilled water, the lowest nutrient concentration (25\%) used yielded a significant increase in germination percentage (58.5 \pm 5.2 ;

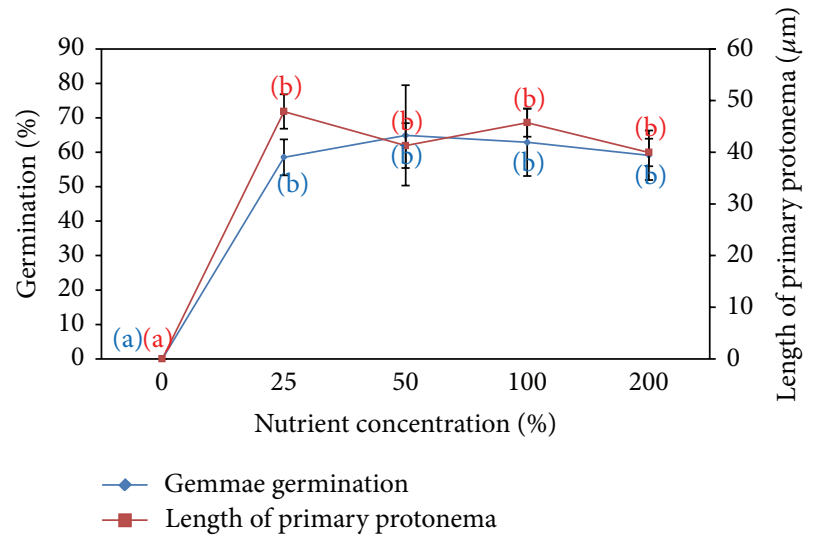

FIGURE 3: Effect of nutrient concentration on gemmae germination (after 5 days) and primary protonema growth (after 6 days) of $C$. erosum. Points are means of three replicates. Vertical bars represent standard error. Values with the same alphabets along the same curve are not statistically different at $1 \%$ probability.

$P=0.006)$. Increasing the nutrient concentration from $25 \%$ up to $200 \%$ did not result in statistically significant $(P>0.05)$ increase in germination of the gemmae. Similarly, statistical analysis reveals a significant difference in protonema growth among the different nutrient conditions $(F(4,10)=44.3$; $P<0.01)$. No protonema were produced in distilled water $(0 \%)$ and the $25 \%$ nutrient gave rise to a significantly (47.9 $\pm 3.4 \mu \mathrm{m} ; P<0.01)$ higher growth. The post hoc test shows that no further increase in protonema length occurred with increasing nutrient concentration from $25 \%$ up to $200 \%$.

\section{Discussion}

Germination and establishment are crucial stages in the life cycle of a plant $[13,14]$ especially for the bryophytes which must survive an array of habitat conditions mainly on only one set of chromosomes. Germination of bryophyte spores has been reported to be limited by habitat $\mathrm{pH}$. While the spores of Funaria hygrometrica and Tetraplodon mnioides germinated best in alkaline substrates, being retarded by acidic $\mathrm{pH}$ [15], optimum germination and thallus growth of the liverworts, Plagiochasma appendiculatum and Reboulia hemisphaerica occurred at $\mathrm{pH}$ of 6.0 [16]. This study shows that germination in the gemmae of the tropical moss C. erosum is limited by $\mathrm{pH}$. The gemmae germinated best in acidic conditions, forming a peak at $\mathrm{pH} 4$, but performed poorly at substrate $\mathrm{pH}$ values above 5 in this study. This finding is consistent with the report of Odu [9] on gemmae germination of two other tropical mosses in which he attributed the rapid spread of Barbula indica to the high rate of gemmae germination of the moss which was, in turn, favoured by the alkaline nature of their substrate. Germination of the gemmae of Bryum nitens, in that report, was however suppressed by similar alkaline $\mathrm{pH}$ values but performed well in low $\mathrm{pH}$.

The gemmae of the tropical C. erosum germinate to form filamentous protonemata. Elsewhere, in Funaria hygrometrica, reducing substrate $\mathrm{pH}$ to 5.5 resulted in the extension of the protonemal tip cells, whereas increasing the $\mathrm{pH}$ to 6.8 
prevented further growth [10]. Also, in Buxbaumia viridis optimum protonemal growth occurred at $\mathrm{pH} 5$ while that of Neckera pennata was greatest at $\mathrm{pH}$ 6.5-7 [17]. In this study, however, optimum protonema growth occurred at $\mathrm{pH}$ range of 4-5, while higher $\mathrm{pH}$ values between 6 and 7 retarded growth significantly.

The process of gemmae germination to protonema growth to formation of leafy shoots in C. erosum may require increasingly more specific conditions. Although $\mathrm{pH} 2$ and 3 in this study resulted in very high germination figures, the poor primary protonemal growth at those values indicates that conditions suitable for germination are not necessarily conducive for protonema development. This observation is consistent with the report of Forman [18] that although spore germination in Tetraphis pellucida requires a $\mathrm{pH}$ of 3.0-7.3, growth of the leafy shoot occurs in the much narrower $\mathrm{pH}$ range of 5.1-5.8. A similar observation was also made by Wiklund and Rydin [17] that low $\mathrm{pH}$ has a stronger effect on protonema growth than on spore germination.

The observed effects of $\mathrm{pH}$ on the germination and protonema growth in C. erosum may be linked indirectly to its effects on the solubility and availability of certain ions in the substrate, resulting in toxic effects. For example, a high level of calcium is generally associated with high $\mathrm{pH}$ [10]. While calcium enhances germination in Plagiochasma appendiculatum [19] and promotes protonema production in Stereophyllum radiculosum [20], it has been reported to depress germination in Dicranella cerviculata [21].

Studies on the effect of photoperiod on higher plants suggest that increased day length gave rise to more photosynthesis, resulting in longer stems and increased elongation rates [10]. In the moss Bryum pseudotriquetrum, photoperiod affected development, requiring more than 5 hours of day length for spore germination and protonema growth [22]. In contrast with the tropical moss in this study, a significant gemmae germination and growth of primary protonema occurred in the moss when exposed to the first 3 and 6 hours of natural light, respectively. This observation indicates the moss is able to realize a net photosynthetic carbon gain during the first few hours of the day. Increasing exposure up to 12 hours did not give a better result. Photoinhibition, resulting from the daily variation in light intensity, is a likely culprit. The resumption of growth in primary protonema, when left in natural light beyond 12 hours, is indicative of a full recovery of the moss from photodestruction of pigments by late evening and possibly, an adaptation to high light intensity.

The chlorophyllose gemmae of C. erosum did not germinate in the dark, indicating further that the gemmae require light to germinate. This observation is consistent with the report on Polytrichum commune spores which germinated only in light or in darkness when sucrose is present [23]. This indicates the need for light is likely prompted by a need for energy, given also that any growth after germination will necessarily require energy. Earlier on, Szweykowska [24], after inducing bud formation in Ceratodon purpureus in the dark, using kinetin, reported that kinetin gave rise to an effect similar to that of light. Thus the presence of light might be to induce the production of a cytokinin. However, since neither kinetin nor sucrose is light-sensitive, the involvement of a phytochrome-mediation is likely. This requirement of light for germination in C. erosum could be an adaptive strategy to ensure the gemmae remain where they have landed until conditions become suitable for further development thus preventing germination from occurring underground or under heavy leaf-litter, where light is completely absent.

Field studies [25] indicate that germination in Funaria hygrometrica and Ceratodon purpureus may be nutrientlimited. Earlier on, Arnaudow [26] reported that Dicranum scoparium spores failed to germinate in water, but when earth particles were added to the water, they germinated in two days. Also Olarinmoye [27], in a study on Radula flaccida, found that when grown in distilled water, the liverwort turned chlorotic and frail indicating the plant, most likely, was using nutrient reserves. The gemmae of C. erosum in this study did not germinate in distilled water. This failure to germinate in distilled water is likely a survival strategy permitting them to remain in their new location until conditions become suitable for development.

The moss under study attained as much germination and protonema growth with $25 \%$ nutrient as it did with all the other higher nutrient concentrations, indicating C. erosum is adapted to low nutrient conditions. This observation is consistent with the report of Vitt [28] on some boreal mosses which exhibited no less productivity in poor fens than in nutrient-rich fens. Low nutrient requirements for optimum growth have also been reported for the liverwort Radula flaccid [27]. Several authors, in comparing bryophytes to other plants, have reported lower nutrient requirements for development in bryophytes than in other plants [29-35]. This adaptation to low nutrients could be linked to their ability to relocate soluble nutrients from older tissues to young and growing parts and is suggestive of the moss' ability to survive in places rather inhabitable by other plants.

This study has shown that $C$. erosum gemmae are adapted to low nutrients and will not germinate or grow any faster in nutrient-rich substrate than in relatively lower nutrient conditions. It may germinate well at substrate $\mathrm{pH}$ as low as 2 , but the probability of establishment will remain limited until pH level improves to 4 or 5 . Gemmae that are completely covered by debris or litter have little chance of establishment if they germinate at all. Germination in the gemmae and protonema growth of the moss occur mostly during morning and late evening hours in this site. The study indicates moss is able to achieve net photosynthetic carbon gain during the morning hours and although afternoon light intensities may limit germination and protonemal growth, significant recovery is very likely by late evening.

\section{Conflict of Interests}

The authors declare that there is no conflict of interests regarding the publication of this paper.

\section{Acknowledgment}

The authors wish to thank the Atmospheric Research Group of the Physics and Engineering Physics Department, Obafemi 
Awolowo University, for assisting them with recorded data on Sunlight.

\section{References}

[1] J.-P. Frahm and D. Klaus, "Bryophytes as indicators of recent climate fluctuations in Central Europe," Lindbergia, vol. 26, no. 2, pp. 97-104, 2001.

[2] H. Korpelainen and N. S. Allen, "Genetic variation in three species of epiphytic Octoblepharum (Leucobryaceae)," Nova Hedwigia, vol. 68, no. 3-4, pp. 281-290, 1999.

[3] S. Laaka-Lindberg, H. Korpelainen, and M. Pohjamo, "Dispersal of asexual propagules in bryophytes," Journal of the Hattori Botanical Laboratory, no. 93, pp. 319-330, 2003.

[4] R. E. Longton, "Reproductive biology and evolutionary potential in bryophytes," Journal of Hattori Botanical Laboratory, vol. 41, pp. 205-223, 1976.

[5] R. E. Longton, "Reproductive biology and variation patterns in relation to bryophyte taxonomy," Nova Hedwigia, vol. 71, pp. 3137, 1982.

[6] P. M. Selkirk, "Vegetative reproduction and dispersal of bryophytes on subantarctic Macquarie Island and in Antarctica," Journal of Hattori Botanical Laboratory, vol. 55, pp. 105-111, 1984.

[7] W. C. Steere, "Antarctic bryophyta," BioScience, vol. 15, no. 4, pp. 283-285, 1965.

[8] W. D. Reese, "Substrate preference in Calymperaceae: Calymperes, Mitthyridium, and Syrrhopodon," The Bryologist, vol. 104, no. 4, pp. 582-592, 2001.

[9] E. A. Odu, "On the gemmae of West Tropical African mosses," Symposia Biologica Hungarica, vol. 35, pp. 215-225, 1987.

[10] J. M. Glime, Bryophyte Ecology. Volume 1: Physiological Ecology, Ebook, Michigan Technological University and the International Association of Bryologists, 2007, http://www.bryoecol.mtu.edu/.

[11] R. N. Chopra and K. Rahbar, "Temperature, light and nutritional requirements for gametangial induction in the moss Bartramidula bartramioides," New Phytologist, vol. 92, no. 2, pp. 251-257, 1982.

[12] R. Reski and W. O. Abel, "Induction of budding on chloronemata and caulonemata of the moss, Physcomitrella patens, using isopentenyladenine," Planta, vol. 165, no. 3, pp. 354-358, 1985.

[13] G. S. Gomes, Á. M. Randi, Â. Puchalski, D. D. S. Santos, and M. S. Dos Reis, "Variability in the germination of spores among and within natural populations of the endangered tree fern Dicksonia sellowiana Hook. (Xaxim)," Brazilian Archives of Biology and Technology, vol. 49, no. 1, pp. 1-10, 2006.

[14] F. Socolowski, D. C. M. Vieira, and M. Takaki, "Interaction of temperature and light on seed germination in Tecoma stans $\mathrm{L}$. Juss. ex Kunth (Bignoniaceae)," Brazilian Archives of Biology and Technology, vol. 51, no. 4, pp. 723-730, 2008.

[15] T. V. Armentano and J. D. Caponetti, "The effect of $\mathrm{pH}$ on the growth of protonemata of Tetraplodon mnioides and Funaria hygrometrica," The Bryologist, vol. 75, no. 2, pp. 147-153, 1972.

[16] K. S. Vishvakarma and A. Kaul, "Culture studies on Plagiochasma appendiculatum Lehm. et Lindenb. and Reboulia hemisphaerica (L.) Raddi populations of Pachmarhi (central India) in relation to $\mathrm{pH}$ on a comparative basis," Cryptogamie Bryologie Lichenologie, vol. 9, pp. 129-135, 1988.

[17] K. Wiklund and H. Rydin, "Ecophysiological constraints on spore establishment in bryophytes," Functional Ecology, vol. 18, no. 6, pp. 907-913, 2004.
[18] R. T. T. Forman, "Growth under controlled conditions to explain the hierarchical distributions of a moss Tetraphis pellucida," Ecological Monographs, vol. 34, no. 1, pp. 1-25, 1964.

[19] K. S. Vishvakarma, A. Kaul, and D. K. Sharma, "Culture studies on spore germination of two liverworts," Yushania, vol. 4, pp. $1-4,1987$.

[20] S. O. Olarinmoye, A. Egunyomi, and A. O. Akande, "Spore germination and protonema development in Stereophyllum radiculosum (Hook.) Mitt," Journal of Hattori Botanical Laboratory, vol. 50, pp. 95-106, 1981.

[21] A. Vaarama and N. Tarén, "On the separate and combined effects of calcium, kinetin and gibberellic acid on the development of moss protonemata," Journal of the Linnean Society of London, Botany, vol. 58, no. 373, pp. 297-304, 1963.

[22] K. Kinugawa and S. Nakao, "Note on spore germination and protonemal growth controlled by day length in Bryum pseudotriquetrum," Botanical Magazine (Tokyo), vol. 78, pp. 194197, 1965.

[23] L. W. Hahn and J. H. Miller, "Light dependence of chloroplast replication and starch metabolism in the moss Polytrichum commune," Physiologia Plantarum, vol. 19, no. 1, pp. 134-141, 1966.

[24] A. Szweykowska, "Kinetin-induced formation of gametophores in dark cultures of Ceratodon purpureus," Journal of Experimental Botany, vol. 14, no. 1, pp. 137-141, 1963.

[25] P. A. Thomas, M. C. F. Proctor, and E. Maltby, “The ecology of severe moorland fire on the North York Moors: chemical and physical constraints on moss establishment from spores," Journal of Ecology, vol. 82, no. 3, pp. 457-474, 1994.

[26] N. Arnaudow, "Über Transplantieren von Moosembryonen," Flora, vol. 118/119, pp. 17-26, 1925.

[27] S. O. Olarinmoye, "Ecological studies on epiphyllous liverworts in western Nigeria. II. Notes on competition and successional changes," Revue Bryologique et Lichénologique, vol. 41, pp. 457463, 1975.

[28] D. H. Vitt, "Growth and production dynamics of boreal mosses over climatic, chemical and topographic gradients," Botanical Journal of the Linnean Society, vol. 104, pp. 35-59, 1990.

[29] P. R. Burkholder, "Organic nutrition of some mosses growing in pure culture," The Bryologist, vol. 62, no. 1, pp. 6-15, 1959.

[30] M. F. Dietert, "Studies on the gametophyte nutrition of the cosmopolitan species Funaria hygrometrica and Weissia controversa," The Bryologist, vol. 82, no. 3, pp. 417-431, 1979.

[31] R. F. Griggs and D. Ready, "Growth of liverworts from Katmai in nitrogen-free media," American Journal of Botany, vol. 21, no. 5, pp. 265-277, 1934.

[32] W. Larcher, Physiological Plant Ecology, translated by M. A. Biederman-Thorson, Springer, Berlin, Germany, 1983.

[33] W. Larcher, Physiological Plant Ecology. Ecophysiology and Stress Physiology of Functional Groups, Springer, Berlin, Germany, 3rd edition, 1995.

[34] A. L. D. Southorn, "Bryophyte recolonization of burnt ground with particular reference to Funaria hygrometrica. II. The nutrient requirements of Funaria hygrometrica," Journal of Bryology, vol. 9, no. 3, pp. 361-373, 1977.

[35] B. M. Svensson, "Competition between Sphagnum fuscum and Drosera rotundifolia: a case of ecosystem engineering," Oikos, vol. 74, no. 2, pp. 205-212, 1995. 

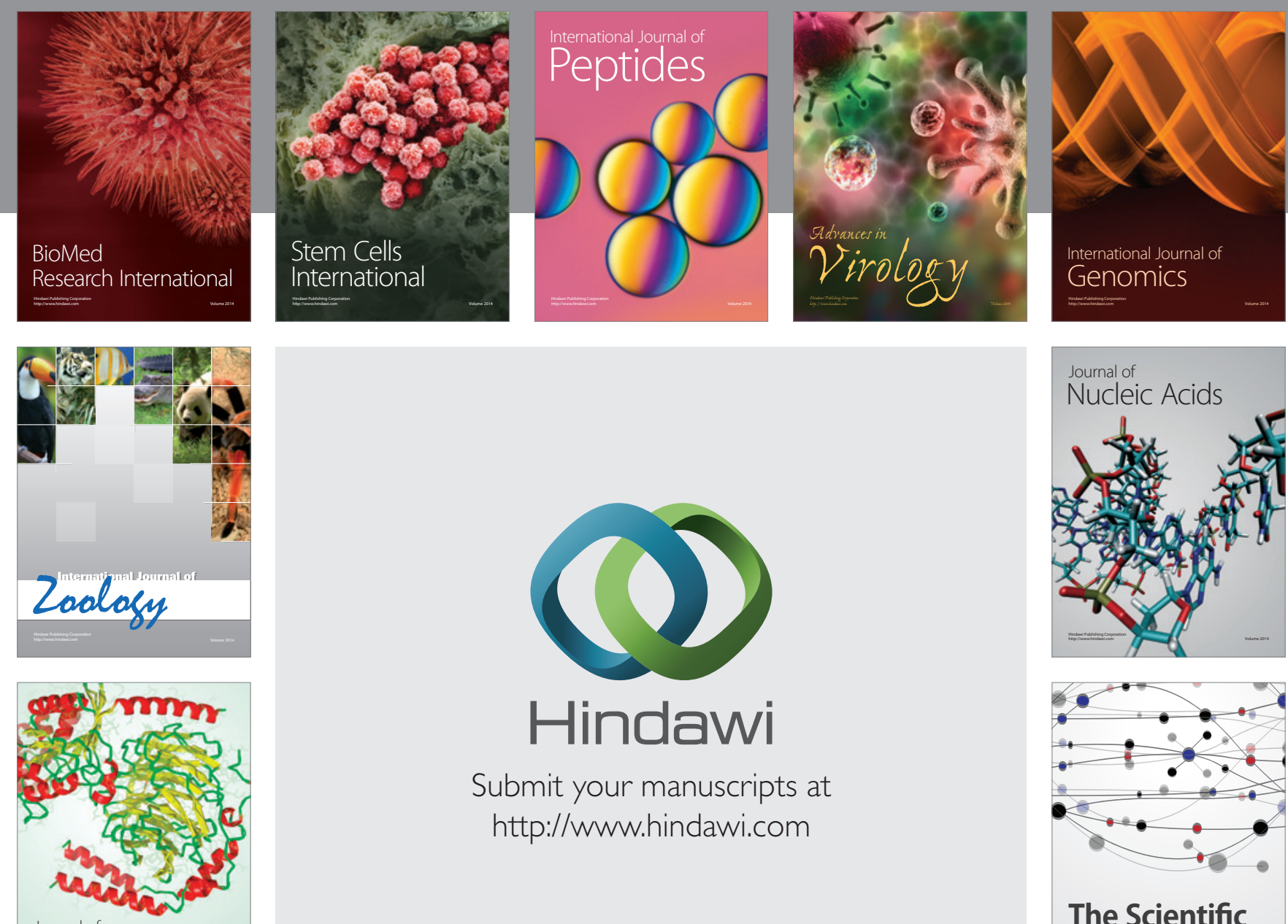

Submit your manuscripts at

http://www.hindawi.com

Journal of
Signal Transduction
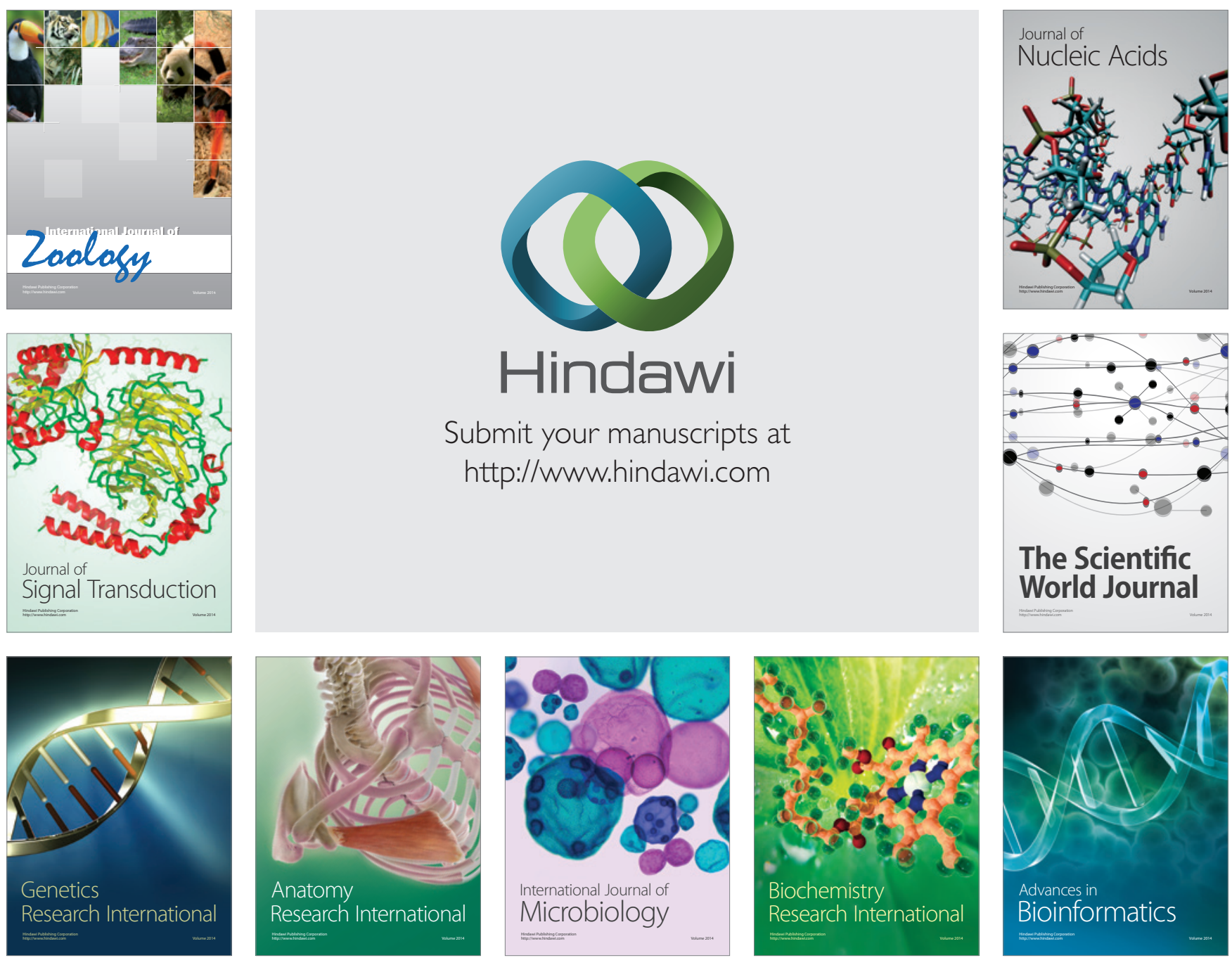

The Scientific World Journal
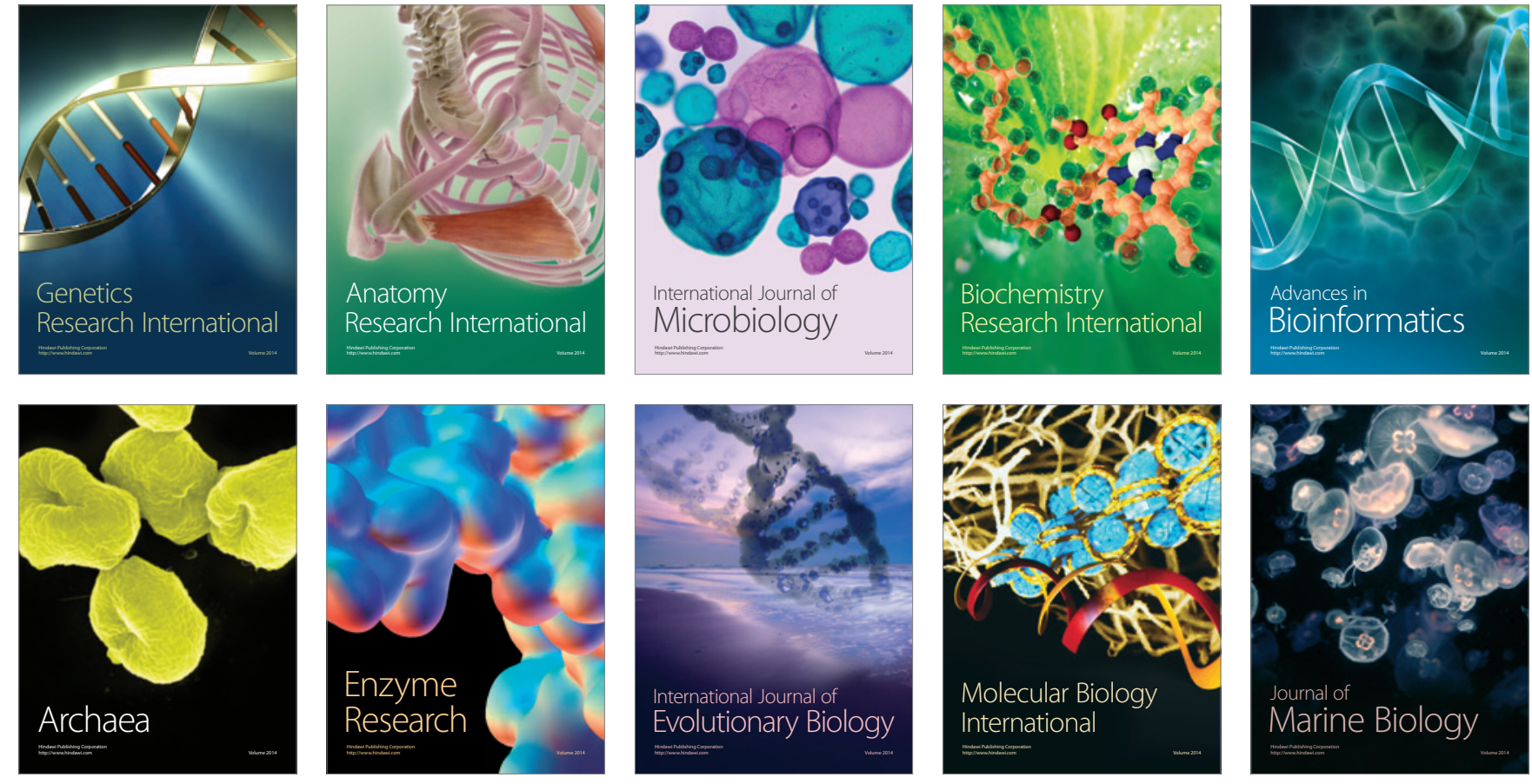